JURNALYOGA DAN KESEHATAN

JURUSAN YOGA KESEHATAN

FAKULTAS BRAHMA WIDYA

IHDN DENPASAR
Vol. 3 No. 2 September 2020

ISSN : 2621-0185 (Cetak)

ISSN : 2722-9440 (Online)

http://ejournal.ihdn.ac.id/index.php/jyk

\title{
Estetika Ekologi Pada Yoga Surya Tradisi Watukaru Di Pasraman Seruling Dewata Desa Pakraman Bantas, Kecamatan Selemadeg Timur, Kabupaten Tabanan
}

\author{
I Wayan Nerta \\ Institut Hindu Dharma Negeri Denpasar \\ email : wayannerta10@gmail.com
}

Diterima tanggal 13 Agustus 2020, diseleksi tanggal 16 Agustus 2020, dan disetujui tanggal 28 Agustus 2020

\section{ABSTRACT}

Yoga is the reunification of all thoughts, intellect, feelings, emotions, instincts, and other traits. Asana is steady, calm and comfortable posture. The yoga āsana movements contained in it are quite beneficial for the body and mind. The inspiration from the yoga assana movement is also inseparable from the forms of living beings and nature. Every object in the universe and organic object forms has its own amazing structure. Thus, through an aesthetic approach, it is known the value of beauty, various forms, and the influence of internalization and modification of natural movements and living beings in āsana yoga. Maintaining the body to keep it clean, healthy and strong is a daily duty and responsibility. Solar yoga is a yoga attitude as a way to increase spiritual awareness and enlightenment by respecting and worshiping the sun. Pasraman Seruling Dewata is one of the non-formal institutions to study Hinduism in relation to the existence of Balinese cultural traditions. Many classical Yoga teachings are taught there, the Watukaru tradition of solar yoga is one of them. The solar yoga movement has benefits and meaning as well as ecological aesthetic value. Based on this, it is necessary to know the form of the Watukaru tradition solar yoga, the internalization of ecological aesthetics in the Watukaru tradition solar yoga and the implications of the Watukaru tradition of solar yoga for students at Pasraman Seruling Dewata, Pakraman Bantas Village, East Selemadeg District, Tabanan Regency.

Key words: ecological aesthetics; solar yoga; the watukaru tradition

\section{ABSTRAK}

Yoga adalah penyatuan kembali semua pikiran, intelektual, rasa, emosi, insting, dan sifatsifat lainnya. Asana adalah sikap tubuh yang mantap, tenang dan nyaman. Gerakan yoga āsana yang terdapat di dalamnya cukup banyak memberikan manfaat bagi tubuh dan pikiran. Inspirasi dari gerakan yoga āsana ini juga tak lepas dari bentuk-bentuk makhluk hidup dan alam. Setiap objek di alam semesta dan bentuk objek organik memiliki struktur tersendiri yang begitu mengagumkan. Sehingga, melalui pendekatan estetik diketahui nilai keindahan, berbagai bentuk, dan pengaruh internalisasi dan modifikasi gerak alam dan makhluk hidup dalam yoga āsana. Memelihara tubuh agar senantiasa bersih, sehat dan kuat adalah menjadi kewajiban dan tanggung jawab sehari-hari. Yoga surya merupakan salah satu sikap yoga sebagai jalan untuk meningkatkan kesadaran serta pencerahan spiritual dengan cara menghormati dan memuja 
matahari. Pasraman Seruling Dewata merupakan salah satu lembaga non formal untuk mempelajari agama Hindu dalam kaitannya dengan keberadaan tradisi Budaya Bali. Ajaranajaran Yoga yang klasik banyak diajarkan disana, yoga surya tradisi Watukaru salah satunya. Gerakan yoga surya memiliki manfaat dan makna serta nilai estetika ekologi. Berdasarkan hal tersebut perlu mengetahi bentuk yoga surya tradisi Watukaru, Internalisasi estetika ekologi dalam yoga surya tradisi Watukaru dan implikasi yoga Surya tradisi Watukaru terhadap siswa di Pasraman Seruling Dewata Desa Pakraman Bantas, Kecamatan Selemadeg Timur, Kabupaten Tabanan.

Kata kunci: estetika ekologi; yoga surya; tradisi Watukaru.

\section{PENDAHULUAN}

Alam semesta ini adalah hasil ciptaan Tuhan yang mengagumkan. Tuhan mengatur segala sesuatunya dengan sempurna sehingga manusia tidak mampu mengungkap rahasia yang terjadi di seluruh jagat raya. Yoga merupakan cara untuk mencapai keselarasan antara badan fisik, pikiran dan jiwa atau roh karena gerakan yoga dapat mempengaruhi fisik dan mental untuk menjadi sehat, sehingga jiwa terkonsentrasi. Maka peranan yoga di sini sangat jelas membawa pikiran menjadi tentram dan merenungkan kebebasan jiwa yang abadi (Somvir, 2007: 17). Manusia sebagai mahluk individu merupakan kesatuan antara jiwa dengan badan, kesatuan antara psikis dengan fisik, sehingga terdapat suatu ungkapan, bahwa di dalam jiwa yang sehat terdapat badan yang sehat dan di dalam badan yang sehat terdapat jiwa yang sehat. Manusia tidak dapat berkembang menjadi manusia seutuhnya tanpa lingkungan alam. Ia tentu tidak dapat hidup tanpa alam semesta, tanpa air, tanpa udara, tanpa hutan, tanpa tanah, tanpa hutan, tanpa laut dan seluruh biota, flora dan fauna di alam ini (Sony Keraf dalam Putra, 2020 : 108).

Maharsi Patanjali dalam kitabnya Yogasutra (I: 2) mendefinisikan yoga: yogas citta vritti nirodhah. Artinya, yoga adalah mengendalikan gerak-gerik pikiran, atau cara untuk mengendalikan tingkah polah pikiran yang liar, dan lekat terpesona oleh aneka ragam objek yang dikhayalkan memberi nikmat. Memelihara tubuh agar senantiasa bersih, sehat dan kuat adalah menjadi kewajiban dan tanggung jawab sehari-hari. Gerakan yoga surya merupakan jalan yoga untuk meningkatkan kesadaran serta pencerahan spiritual dengan cara menghormati dan memuja matahari. Yoga surya telah ada sejak zaman Veda dan matahari dijadikan simbol yang kuat untuk membangkitkan aspek keberadaan matahari di dalam diri kita. Yoga surya berupa gerakan yang dinamis dan berenergi yang digerakkan secara berurutan dengan irama yang stabil dan pose ini mencerminkan irama alam semesta.

Yoga surya dianggap sebagai latihan rohani yang lengkap karena meliputi asana, pranayama, mantra, dan teknik meditasi. Surya artinya penghormatan pada Dewa Matahari, dapat dilihat sebagai bentuk pemujaan terhadap Dewa Matahari, dan semuanya itu tampil pada 
tingkat mikro maupun makrokosmis, yang merupakan teknik penting dalam melaksanakan yoga. Kelentukan tubuh merupakan cara yang sangat penting untuk memperoleh hidup sehat, kuat dan aktif yang merupakan persiapan untuk membangkitkan spiritual dan kesadaran.

Asal-usul terbentuknya dan kinerja gerakan yoga dianggap sebagai sebuah ritme dan menjadi responsi terhadap keseimbangan alam. Inspirasi yang datang dari gerakan yoga surya ini juga tak lepas dari bentuk-bentuk alam. Setiap objek di alam semesta dan bentuk objek organik memiliki struktur tersendiri yang begitu mengagumkan. Sesuai dengan teori art by metamorphosis: perubahan bentuk (fungsi), keseluruhan gerakan dari yoga surya merupakan representasi dari pencerapan rasa lango (keindahan) yang begitu mendalam dikarenakan adanya interaksi harmoni para yogi dengan mahluk hidup dan lingkungan. Sinergi dari dua konsep keindahan dan interaksi harmoni ini inherent sebagai estetika ekologi. Estetika mengandung pengertian yang umum digunakan adalah, hasil pencerapan, komunikasi, dan kontak rasa (indah dan seni) yang dapat merangsang serta membangkitkan pengalaman atau kenikmatan yang bersifat kontemplatif dan transendental (Dibia, 2012). Tubuh manusia yang menjadi inspirasi besar dalam berbagai karya tentunya tidak hanya menjadi objek saja, tetapi juga perlu menjadi subjek bagi dirinya sendiri yang memiliki rasa estetika.

Aktivitas yoga khususnya yoga Surya tradisi Watukaru Pasraman Seruling Dewata ini sebagai salah satu sarana bagi tubuh dalam mengeksplorasi dirinya. Di dalam gerakan yoga Surya, terdapat komposisi bentuk tubuh manusia yang merupakan upaya dari meniru suatu objek alam yang di dalamnya terdapat makhluk hidup mempertahankan kehidupannya dengan mengadakan hubungan antar makhluk hidup dan dengan benda tak hidup di dalam tempat hidupnya atau lingkungannya. Termasuk mempelajari perpindahan energi dan materi dari makhluk hidup yang satu ke makhluk hidup yang lain ke dalam lingkungannya dan faktor-faktor yang menyebabkannya. Perubahan populasi atau spesies pada waktu yang berbeda dalam faktorfaktor yang menyebabkannya, terjadi hubungan antarspesies (interaksi antarspesies) makhluk hidup, dan hubungan antara makhluk hidup dengan lingkungannya yang memiliki keindahan sebuah keharmonisan (Wawancara 20 September 2018 : Guru Sesepuh IX Seruling Dewata Ki Kt. Nantra). Hal ini juga disampaikan oleh Putra (2020:107) Kaca mata relasi ke alam, melihat manusia sebagai mahluk lingkungan (homo ecologus). Maksudnya manusia adalah bagian yang tak terpisahkan dari suatu ekosistem, sehingga secara naluriah manusia memiliki kecenderungan untuk selalu memahami akan lingkungannya.

Pasraman Seruling Dewata merupakan salah satu lembaga untuk mempelajari agama Hindu dalam kaitannya dengan memperkaya, melestarikan, dan mengembangkan keberadaan tradisi Budaya Bali secara turun temurun. Lembaga ini merupakan satu-satunya Pasraman yang 205 | YOGA DAN KESEHATAN Vol. 3 No. 2, September 2020 
masih mewarisi tradisi Veda. Ajaran-ajaran Yoga yang klasik banyak diajarkan, salah satunya adalah yoga surya. Ada sedikit perbedaan dalam gerakan yoga Surya yang ada di Pasraman Seruling Dewata. Tentunya setiap gerakan tersebut memiliki manfaat dan makna serta nilai keindahan tersendiri.

\section{PEMBAHASAN}

\subsection{Bentuk Yoga Surya Tradisi Watukaru Di Pasraman Seruling Dewata}

Kata Yoga secara etimologi berasal dari bahasa Sansekerta dari akar kata "yuj" yang artinya hubungan, menghubungkan (Saraswati, 2005: 5). Dalam pengertian ini yoga merupakan suatu cara untuk mencapai suatu kesempurnaan yaitu Dharma dan Moksa dengan memusatkan pikiran kepada Ida Sang Hyang Widhi Wasa (Tuhan Yang Maha Esa), sehingga secara perlahanlahan akan dapat membebaskan diri dari ikatan-ikatan keduniawian. Jalan yoga bukanlah suatu latihan keahlian, melainkan suatu pengakuan dan pengabdian dengan dorongan batin untuk mengembangkan diri.

Surya juga berarti penghormatan pada Dewa Matahari, dapat dilihat sebagai bentuk pemujaan terhadap Dewa Matahari, dan semuanya itu tampil pada tingkat mikro maupun makrokosmis. Surya merupakan teknik penting dalam melaksanakan yoga (Satyananda, 2002: 03). Kelentukan tubuh dari beryoga sangat bermanfaat untuk memperoleh hidup sehat, merupakan persiapan untuk membangkitkan spiritual dan kesadaran. Yoga Surya lebih dari sekedar rangkaian latihan fisik, yang di dalamnya terdapat peregangan, pemijatan, memperkuat dan merangsang seluruh otot, organ vital dan bagian fisik dengan menggerakkan tubuh ke depan dan kebelakang secara bergantian. Ia juga memiliki kedalaman dan kesempurnaan sebagai suatu latihan spiritual.

Yoga Surya terdiri 12 rangkaian yoga yang dinamakan Yogacara. Uniknya setiap Yogacara dari ke 12 Yogacara Surya masing-masing terdiri dari 12 rangkaian gerakan yoga asana. Para sulinggih di Bali juga melakukan pemujaan kepada Surya disebut Surya Sewana. Namun para sulinggih tidak melakukan Yoga asana Surya Namaskara setiap harinya, tetapi dalam bentuk doa pemujaan Surya Sewana setiap pagi hari. Apabila kedua ini beliau lakukan Surya Namaskara dan Surya Sewana setiap pagi maka derajat kesehatan para Sulinggih akan meningkat. Surya Sewana sebagai doa pada bhuwana agung sedangkan Surya Namaskara sebagai upaya meningkatkan kesehatan pada bhuwana alit.

Yoga Surya tradisi Watukaru adalah yang dinamakan Yogacara merupakan kebiasaan yang terus dipelihara dan ditaati sebagai suatu nilai-nilai luhur Bali kuno peninggalan Pertapaan Candra Parwata di gunung Batukaru. Tempat lokasi yang indah, terletak di lereng gunung 
Batukaru bersuhu sejuk berkisar antara $24-32{ }^{\circ} \mathrm{C}$ (siang hari) dan $18-22{ }^{\circ} \mathrm{C}$ (malam hari). Gerakan Yoga Surya tradisi Watukaru terdiri dari beberapa struktur latihan dengan beberapa tahapan sebagai berikut .

Ada beberapa tahapan dalam latihan, diawali dengan sebuah doa Gayatri Mantram, Mertyum Jaya Mantram dan Maha Mertyum Jaya Mantram. Rangkaian doa awal diakhiri dengan Mantram Puja Guru. Doa awal pelatihan sebagai upaya mohon keselamatan di dalam proses pelatihan. Doa merupakan suatu tindakan rekolektif, artinya dengan itu manusia menetapkan dan memupuk kesatuan dengan Tuhan. Doa merupakan bentuk pemujaan universal, dengan diam ataupun dengan suara, pribadi maupun umum, spontan maupun menurut aturan (Dhavamony, 1995: 241 dalam Sugata, 2012).

\subsubsection{Peregangan / Pawana Muktasana.}

Pavana berarti 'angin'; mukta berarti 'membebaskan'; dan asana berarti 'sikap badan'. Oleh karena itu Pavanamuktasana adalah sekelompok latihan yang membebaskan angin dan gas dari tubuh. Rangkaian Pavanamuktasana sangat sederhana, namun rangkaian tersebut paling efektif dalam mengatur apa yang di India dikaitkan sebagai watak : lendir (kapha), angin (vata), dan asam atau empedu (pitta) (Saraswati, 2002:19). Menurut ilmu pengobatan kuno yang dikenal dengan Ayurveda, tiga kecenderungan ini mengatur semua fungsi tubuh. Jika suatu ketidakberesan muncul pada fungsi tubuh mereka, maka reaksi negatif terjadi pada metabolisme tubuh dan mengakibatkan penyakit.

Latihan peregangan sangat perlu dilakukan oleh seseorang yang akan melakukan latihan yoga atau olah raga. Peregangan otot adalah suatu usaha untuk memperpanjang-panjang otot istirahat (relaksasi) sehingga menjadi tegang, dengan adanya peregangan ini kelentukan (flesibilitas) otot menjadi meningkat (Nala,1992:28). Dengan tubuh yang lentuk maka gerakan tubuh menjadi lebih lentuk, sehingga dapat meningkatkan luas gerakan tubuh. Latihan-latihan yoga sangat diperlukan tubuh yang lentuk untuk mencapai gerakan otot tubuh yang lebih luas. Sehingga peregangan otot sebelum latihan merupakan langkah awal yang tidak boeh diabaikan. Kelentukan tubuh juga dapat mengurangi resiko cedra otot pada waktu latihan, baik latihan yoga maupun olah raga.

\subsubsection{Pemujaan Dewa Surya (Surya Namaskara)}

Matahari merupkan sumber energi alam semesta. Surya Namaskara juga berarti pemujaan kepada Dewa Matahari sebagai pemberi kekuatan tunggal bagi kehidupan yang ada di alam Jagat Raya ini. Surya Namaskara terdiri dari 12 sikap badan, masing-masing berhubungan 
dengan salah satu dari 12 lambang zodiak (Saraswati, 2002 : 133). Asana dengan kedua tangan membungkuk ke belakang bergantian, melenturkan dan meregangkan tulang belakang dan anggota badan pada rentang maksimumnya. Rangkaian gerakan ini memberikan peregangan mendalam pada seluruh tubuh. Berlatih Surya Namaskara secara teratur merupakan salah satu metode yang paling cepat untuk mendapatkan tubuh yang lentur.

Melakukan kegiatan Yoga merupakan pencegah stress dan terbukti menjadi dasar dari suatu terapi yang sangat ampuh bagi penyakit fisik maupun mental. Satyananda Saraswati (2002: 148) tidak ada cara yang lebih baik untuk menghilangkan syaraf, stres dan kegelisahan selain dengan melakukan Surya Namaskara secara teratur. Surya Namaskara merupakan bagian yang tak terpisahkan dari pendekatan Yoga dan mudah dapat diterapkan dalam kehidupan kita sehari-hari. Latihan Surya Namaskara apabila dilakukan tersendiri hanya membutuhkan waktu kira-kira selama 5-15 menit latihan untuk mendapatkan hasil yang sangat cepat dan bermanfaat. Oleh karena itu sangat cocok bagi orang-orang yang aktif seperti para karyawan, pengusaha yang sibuk, ibu rumah tangga yg mengelola keluarga, siswa yang menghadapi pelajaran dan ujian. Demikian juga bagi mereka yang menghabiskan waktunya untuk berpikir seperti para ilmuwan. Asanas Surya Namaskara merupakan latihan inti yang pertama sebelum memasuki Candra namaskara dan gerakan-gerakan atau berbagai pose di dalam Asanas yang dapat melancarkan peredaran darah. Dua belas gerakan Surya Namaskara dalam Yoga Surya tradisi Watukaru adalah sebagai berikut : 1) Pranamâsana (Sikap berdoa) 2). Hasta Uttâsana ( Sikap kedua lengan terangkat). 3). Pâdahastâsana (Sikap membungkuk ke depan). 4) Asva Sancalanasana. 5) Parwatasana. 6). Astangga Namaskara. 7) Bujanggasana. 8) Parwatasana. 9) Asva Sancalanasana. 10 ) Padahastasana. 11) Hasta Utanasana dan 12) Pranamasana. Surya Namaskara pada Yoga Surya tradisi Watukaru dilakukan latihan sebelum melakukanan asana-asana yang lainnya.

\subsubsection{Candra Namaskara.}

Setelah melakukan asana Suryanamaskara selanjutnya dilakukan gerakan asana Candra Namaskara. Terdapat tujuh belas sikap-sikap gerakan Candra Namaskara asana (Nantra, 2010) adalah : 1) Pranamâsana. 2)Hastautanasana. 3)Padahastasana. 4) Utthanâsana (Sikap jongkok) . 5) Arda Candrasana (Tangan ke atas) 6) Aswasancalanasana. 7) Ustrasana (Sikap Unta). 8) Śaśaṅkāsana (sikap kelinci). 9) Bujanggasana. 10) Śaśànkāsana (Sikap kelinci). 11) Ustrasana. 12) Aswasancalanasana. 13) Ardhacandrasana ( Sikap bulan sabit). 14) Utanasana (Sikap Jongkok) 15) Padahastaana. 16) Hastautanasana (Sikap mengangkat kedua lengan ). 17) Pranamasana. 


\subsubsection{Tahapan Akhir}

Setelah melakukan gerakan sikap Suryanamaskara dan Candra Namaskara dilanjutkan dengan pembersihan nadis. Gerakan pembersihan nadis dilakukan dengan memutar telapak tangan sebanyak 108 kali. Bersamaan dengan memutar telapak tangan diikuti dengan mengucapkan Om. Gerakan tangan dari lambat kemudian semakin cepat setelah pada hitungan 108 gerakan terhenti. Sikap pembersihan nadi ini dilakukan sebelum dilakukan meditasi atau semedi, yaitu semedi Mudra Siwa dan semedi Iswara (Wawancara 20 September 2018 : Guru Sesepuh IX Seruling Dewata Ki Kt. Nantra).

Rangkaian tahap selanjutanya dari Yoga Surya tradisi Watukaru adalah buka cakra . Diawali dengan buka cakra Muladara yaitu cakra dasar yang pertama. Gerakan tangan buka Cakra Muladara diawali dengan posisi duduk sikap anjali yang dikuti dengan puja dewa Brahma. Bersamaan dengan melantukan puja dikuti dengan gerakan-gerakan tangan yang indah dan magis sebanyak 10 putaran. Hal ini merupakan ciri dari ada Yoga Surya tradisi Watukaru. Penutup bagian akhir dari rangkaian Yoga Surya Tradisi Watukaru adalah memanjatkan doa pada Tuhan semoga semua mahluk di seluruh alam semesta hidup damai dan berbahagia. Sebuah doa yang dipanjatkan bukan saja untuk diri sendiri, tapi juga untuk semua mahluk di alam semesta ini agar dapat hidup damai dan juga berbahagia.

\subsection{Internalisasi Estetika Ekologi Dalam Yoga Surya Tradisi Watukaru Di Pasraman Seruling Dewata}

Aktifitas Yoga Surya dalam tradisi Watukaru memberikan internalisasi atau nilai dalam estetika ekologi. Gerakan yang indah dalam Yoga Surya memberikan pemaknaan nilai-nilai rasa lango yang mendalam.

\subsubsection{Nilai Pendidikan Estetika Ekologi}

Estetika adalah cabang filsafat yang mempersoalkan seni (art) dan keindahan (beautiful). Estetika berasal dari bahasa Yunani; aisthesis berarti penerapan indrawi, pemahaman intelektual (intelectual underet anding) atau bisa juga kata lain art yang berarti seni, keterampilan, ilmu atau kecakapan, (Rapaf, 1996 : 62). Sedangkan menurut Jelantik (1990) dalam Indrawan (2018) Pengertian "estetika" semula hanya terbatas pada renungan filsafat tentang seni. Teori atau konsep Yunani lama lebih cendrung kepada konsep obyektif, keindahan karya dapat dicapai apabila bagian-bagiannya dapat diatur secara harmonis berdasarkan prinsip-prinsip tertentu. Itulah sebabnya lahir “The great theory of beauty”yang menerapkan prinsip matematika sebagi acuan keindahan arsitektur Yunani. 
Gerakan Yoga Asana memerlukan keterampilan atau kecakapan untuk dapat menguasai setiap pose-posenya. Demikian pula pada gerakan Asanas Yoga Surya tradisi Watukaru merupakan gerakan yang sangat indah dengan kelembutan, kelemasan otot, kelenturan tubuh terbentuk bermacam-macam jenis asanas yang dapat menyerupai berbagai makhluk hidup dalam ekologi di bumi ini. Jika tidak dilatar belakangi oleh rasa seni, tidak mungkin tercipta gerakan asanas yang sangat indah tersebut. Keindahan adalah istilah yang sama pengertiannya dengan istilah beautiful dari bahasa Inggris. Secara objektif keindahan mengacu pada objek atau benda ekologi alam, berupa karya seni, yang memiliki daya tarik atau daya pesona.

Dalam buku Manusia dan Kebudayan dalam Perspektif Ilmu dan Budaya Dasar, dijelaskan pengertian indah sebagai berikut: Indah arti luas ialah keindahan mengandung ide kebaikan, Indah arti luas meliputi keindahan seni, keindahan alam dan keindahan intelektual (Maran, 2000 : 140). Dalam arti estetika murni keindahan, menyangkut pengalaman sesorang akan segala sesuatu yang diserapnya melalui panca indra. Dalam arti sempit, keindahan hanya menyangkut benda-benda yang dapat diserap dengan mata, yang berupa bentuk dan warna (Maran, $2000:$ 141).

Berdasarkan pandangan tersebut di atas, maka Yoga Surya merupakan ciptaan yang mengandung nilai-nilai estetika. Dengan kata lain Yoga Surya tercipta melalui pengamatan spiritual terhadap alam beserta isinya. Dari keindahan alam beserta isinya itu tercipta karyakarya yang indah berupa gerakan-gerakan asana. Dalam hubungan ini dapat dikemukakan contoh asana yang gerakannya yang sangat indah yang terdapat pada Yoga surya tradisi Watukaru yaitu: 1). Parvatāsana merupakan sikap yang menyerupai gunung 2). Bujanggāsana yaitu asana yang menyerupai sikap ular kobra 3). Asvasancalanāsana yaitu Asana yang menyerupai sikap orang seperti menunggang kuda 4). Arda candrāsana yaitu Asana yang menyerupai bulan sabit 5). Sasangkāsansa yaitu asana sikap seperti kelinci.

Gerakan asanas hanya dapat dipraktekkan dalam tubuh manusia, tetapi sikapnya menyerupai pose-pose alam berserta isinya. Hal tersebut merupakan wujud gambaran estetika yang sangat tinggi nilainya yang memberikan rasa lango. Ketika rasa lango dari pengamatan estetika pada alam semesta dibangun rasa lango dalam diri, maka akan memberikan pencerahan dalam diri itu sendiri. Yusida (2017 : 98) nilai estetika ini sangat penting bagi manusia karena dengan keindahan akan memberikan warna dalam kehidupan manusia. Dengan demikian manusia akan merasakan kedamaian dan kenyamanan dalam warna-warni kehidupan. 


\subsubsection{Nilai Pendidikan Etika}

Kata etika berasal dari dua bahasa Yunani yaitu ethos dan ethikos. Ethos berarti sifat, watak, kebiasaan, tempat yang biasa, Ethikos berarti susila, keadaban, atau kelakuandan perbuatan yang baik (Drever, 1988 : 62). Dari uraian di atas yang dimaksud dengan pendidikan etika dalam hal ini adalah norma-norma atau kaidah-kaidah tentang tingakah laku yang baik yang harus dipatuhi oleh setiap siswa kerohanian demi tercapainya tujuan pendidikan rohani .

Etika juga sering disebut dengan moral. Istilah moral berasal dari bahasa latin yaitu mores. Bentuk jamak dari mos yang berarti adat istiadat, watak, kelakuan, tabiat, dan cara hidup, (Drever, 1988 : 62). Jadi etika mempunyai kesamaan pengertian, tetapi di dalam etika hanya watak, tabiat, kebiasaan, cara hidup dan tingkah laku yang baik saja yang disebut etika. Sedangkan dalam kata moral terdapat dua katatagori yaitu moral yang baik dan moral yang buruk.

Etika salah satu Ajaran pokok Agama Hindu, sejalan dengan itu dalam Astangga Yoga, disebutkan Yama dan Niyama sebagai tulang punggung etika Yoga. Yama dan Niyama merupakan sepuluh kode moral atau kebajikan etika yang harus diwujudkan. Dalam Etika tidak mempersoalkan apa dan siapa manusia itu tetapi bagaimana seharusnya manusia berbuat dan bertindak. Jadi tingkah laku yang harus diperhatikan dalam melatih asana pada Yoga Surya sebelum memulai pelatihan merupakan gambaran ajaran etika Yoga yaitu Yama dan Niyama. Yama dalam ajaran Astangga Yoga digambarkan sebagai etika untuk disiplin hidup harmoanis bersama orang lain. Sedangkan Niyama lebih merupkan etika budaya untuk hidup harmonis dengan diri sendiri.

Beberapa hal-hal yang diperhatikan dalam menekuni Yoga Asanas yang merupakan cerminan dari ajaran Yama dan Niyama. Hal tersebut dijabarkan sebagai berikut:

1). Memperhatikan menu makan yang sederhana yaitu bersifat vegetarian; menggunakan pakaian seperlunya agar dapat bergerak dengan mudah di dalam berlatih, merupakan cerminan dari Ahimsa yaitu tidak menyakiti makhluk lain dan Aparigraha yakni tidak berlebihan dalam menikmati benda kesenangan untuk mempertahankan hidup.

2). Memilih lingkungan yang bersih dan mendukung dilaksanakan latihan; berlatih Asanas dengan badan yang bersih dan suci merupakan ajaran dari sauca yang berarti sici lahir dan bathin.

3). Berlatih dengan hati yang gembira dan menghindari ketegangan-ketegangan otot, kekakuan dan rasa tidak enak dalam berlatih, merupakan ajaran Santosa yaitu keadaan mental yang terbebas dari ketegangan dan tekanan. 
4). Dengan berlatih yang tekun yaitu merupakan ajaran Tapah yang berarti melakukan ajaran dengan sungguh-sungguh untuk mencapai suatu tujuan.

5). Melatih Asanas sesuai dengan kondisi tubuh; memperhatikan ketepatan berlatih agar mendapatkan hasil latihan yang maksimal merupakan ajaran Svadyaya yaitu memahami dengan sebaik-baiknya setiap permasalahan rohani (Wawancara 20 September 2018: Guru Sepuh Kt. Nantra).

\section{PENUTUP}

Bentuk yoga surya tradisi Watukaru di Pasraman Seruling Dewata Desa Pakraman Bantas, Kecamatan Selemadeg Timur, Kabupaten Tabanan adalah terdiri tahapan awal, tahapan inti dan tahapan akhir. Pada tahapan awal dimulai dengan doa dengan puja japa mantra. Pada tahap inti dimulai dengan Pawanamuktasana/ Peregangan, Suryanamaskara dan Candra Namaskara. Pata tahap akhir dilakukan gerakan pembersihan nadis dan buka cakra dan ditutup dengan doa melantumkan puja Loka Samesta.

Internalisasi estetika ekologi dalam yoga surya tradisi Watukaru di Pasraman Seruling Dewata Desa Pakraman Bantas, Kecamatan Selemadeg Timur, Kabupaten Tabanan adalah dapat memberikan Nilai Pendidikan Estetika dan Etika. Gerakan asana yang indah menyerupai fose alam semesta beserta isinya. Pengamatan ini memberikan rasa lango keindahan. Ketika rasa lango dari pengamatan estetika pada alam semesta dibangun rasa lango dalam diri, maka akan memberikan pencerahan dalam diri itu sendiri. Keindahan itu memberikan kebahagiaan dan kedamaian. Kedamaian akan tercapai apabila ditunjang dengan hidup harmonis bersama orang lain dan budaya hidup harmonis dengan diri sendiri.

\section{DAFTAR PUSTAKA}

Anandamitra Acarya, Avadhutika, 2001. Yoga untuk Kesehatan, Jakarta Barat : Persatuan Ananda Marga Indonesia.

Basma IB, Sudarma Nengah, 1992. Modul Agama Hindu Penyetaraan Guru-guru Agama Hindu, Jakarta : Dirjen Bimas Hindu dan Budha.

Djelantik, A. A. M. "Peranan Estetika Dalam Perkembangan Kesenian Masa Kini", Mudra, Jurnal Seni Budaya, No. 2, Th. II, STSI Denpasar, 1994, p. 15. Lihat Juga, Fx. Mudji Sutrisno dan Christ Vewrhaak, Estetika Filsafat Keindahan, Penerbit Kanisius, Yogyakarta, 1993, p. 81

Dibia, I Wayan 2012. Taksu dalam Seni dan Kehidupan Masyarakat Bali. Denpasar : Bali Mangsi. 
George Dickie, Aesthetics An Introduction, Pegasus, A Division of Bobbs-Merrill Educational Publishing, Indianapolis, 1979, pp. 149-158. Lihat juga, Dr. A. A. M. Djelantik, Pengantar Dasar Ilmu Estetika, Jilid II, Falsafah Keindahan dan Kesenian, Sekolah Tinggi Seni Indonesia, Denpasar, 1992, pp. 66-68

Gloriani, Yusida (2017) . SIMANTIK, Jurnal Ilmiah Program Studi Bahasa dan Sastra Indonesia.97-113.

Maran, Rafael Raga, 2000. Manusia dan Kebudayaan dalam Persepektif Ilmu Budaya Dasar. Jakarta: Bineka Cipta,

Nala, N. 1992. Kumpulan Tulisan Olahraga. Denpasar: KONI Bali.

Nantra, I Ketut. 2010. Meditasi Candra Kinanti. Bali : Paiketan Paguron Suling Dewata.

Nantra, I Ketut. 2009. Serial Walian Sakti Meditasi Kesehatan Jiwa Premana 2. Surabaya: Paramita.

Pudja, I Gede. 1999. Bhagawadgita (Panca Weda). Surabaya: Paramitha.

Putra, Andreas Maurenis, 202. Pertobatan Ekologis dan gaya Hidup Baru Dalam relasinya dengan Semesta, Sitolus, Jurnal Teologi.

Saraswatī, Svāmī Satya Prakās. 2005. Pātañjali Rāja Yoga (Alih Bahasa : J.B.A.F. Mayor Polak). Surabaya: Parāmita.

Satyananda, Saraswati Svami 2002. Asanas, Pranayama, Mudra, Bandha. Surabaya: Paramita.

Sugata, I Made. "Mistisisme Yoga:Polarisasi Gerakan Spiritualitas Dalam Masyarakat Lintas Agama." Pangkaja (2012): 162-181.

Somvir.2007.Mari Beryoga untuk Badan, Pikiran dan Jiwa. Denpasar:Panakom.

Titib, I Made. 1997. Tri Sandhya,Sembahyang, dan Berdoa, Surabaya: Paramita

West, Richard dan Turner, Lynn H. 2009. Pengantar Teori Komunikasi Analisis dan Aplikasi

(Buku 1). Jakarta: Salemba Humanika.

Wirawan, Komang Indra. "Taksu Dalam Dramatari Calonarangsebuah Kajian Estetika Hindu." Widyadari (2018): 40-45. 